\title{
EVALUATION OF MAIZE GENOTYPES FOR RESISTANCE TO Aspergillus INFECTION AND AFLATOXIN PRODUCTION
}

\author{
RGAS Rajapakse ${ }^{1}$, KM. Karunarathna ${ }^{2}$, P Premarathne ${ }^{1}$, RNI Perera ${ }^{1}$ \\ ${ }^{1}$ Horticultural Crops Research \& Development Institute, Gannoruwa. Peradeniya \\ ${ }^{2}$ Seed Certification and Plant Protection Centre, Gannoruwa, Peradeniya
}

Accepted: $12^{\text {th }}$ July 2010

\begin{abstract}
Maize (Zea mays L) is one of the important food crops grown in Sri Lanka. Kernel infection of maize by $A s$ pergillus flavus and subsequent aflatoxin production is a frequent and serious problem. Genetic resistance for A. flavus infection is the most economical and successful way of controlling infection and subsequent production of aflatoxins. Therefore, a study was undertaken in two locations at Maha Illuppallama to evaluate inbred lines and hybrids for resistance to Aspergillus infection and aflatoxin production. Artificial inoculation increased percentage kernel infection by Aspergillus compared to non-inoculated treatments. Percentage kernel infection by Aspergillus varied with genotypes and no significant relationship between percentage kernel infection and aflatoxin levels was found. Aflatoxin production in some hybrids found to be zero when artificially inoculated with virulent isolates of A. flavus. Commercial hybrids, namely NK 40, Sampath and Pacific grown in Sri Lanka showed susceptibility to aflatoxin production.
\end{abstract}

Keywords: Aflatoxin, Aspergillus flavus, Maize, Resistance

\section{INTRODUCTION}

Maize (Zea mays L) has been introduced to Sri Lanka during $16^{\text {th }}$ century from Mexico and it is one of the major food crops growing in Sri Lanka. Due to the high energy value, protein content and low cultivation cost, it become popular among Sri Lankan farmers and consumers. The annual cultivated extent of maize in Sri Lanka is about 52,000 ha covering many districts under rain fed conditions in the dry zone (AgStat 2006).

Aflatoxin, a secondary metabolite produced by some fungi such as Aspergillus species in grains either before or after harvest and feedstuff is considered a potential hazard to human and animal health, due to their toxicity and carcinogenicity. Aflatoxin contamination also can seriously affect marketing of grain. Aflatoxins B1, B2, G1 and G2 were detected in maize, peanut butter and cocoa (Diener et al. 1987: Hoejskov and Joergensen 1996). Aspergillus ear and kernel rot of maize is caused by $A$. flavus Link:Fr. and the disease along with the associated production of aflatoxin in grains are prevalent in the maize cultivations in years with drought conditions. Maize grain with more than 20 ppb aflatoxin cannot be sold in international market and some countries are not buying grains with aflatoxin contamination greater than 10ppb (Campbell and White 1995).

The most effective control measures of Aspergillus ear and kernel rot and the possible aflatoxin contamination of maize is the use of genetically resistant varieties (Lillehoj 1987). Natural outbreaks of the disease usually are sporadic so that identification of resistant genotypes under natural infection is unreliable (Zuber et al. 1983). Thus, artificial inoculation is preferred but inoculation techniques that produce uniformly high levels of ear rot and aflatoxin must be used (Davis et al., 1986). Differences in Aspergillus infection and aflatoxin production have been observed in commercial maize hybrids, in inbreds and open-pollinated varieties (Campbell and White 1995). Although genotypic resistance to Aspergillus ear rot and aflatoxin production is known, high levels of resistance have not been incorporated into commercially valuable hybrids (Campbell and White, 1995). Therefore this study was undertaken to identify genotypes that are resistant to aflatoxin production due to Aspergillus infection.

\section{MATERIALS AND METHODS}

Isolation of Aspergillus flavus:

Disease affected maize ears were collected from farmer fields in different locations of Anuradhapura, Matale and Monaragala districts. Six isolates were identified from kernels of disease-affected ears by culturing on Potato Dextrose Agar (PDA). Isolates of Aspergillus were collected from mycelia of single conidia cultures grown on PDA. A. flavus was identified by microscopic observations and comparison of morphology of conidia and conidial heads and mycelia colour on PDA (Kenneth et al. 1973).

\footnotetext{
*Corresponding author : sirimewan_hordi@yahoo.com
} 


\section{Aflatoxin production of isolates of Aspergillus flavus:}

The aflatoxin production ability of isolates of $A$. flavus was screened by UV light test. At first clean seeds of maize variety "Sampath" were ground by a specific motorized grinder into small pieces (approximately a seed broken into five pieces) and placed in sterilized petre-plates at the rate of 20 pieces per plate. Conidia suspension $\left(1 \times 10^{6}\right.$ conidia $/ \mathrm{ml}$ ) of each isolate were prepared. One $\mathrm{ml}$ of conidia suspension was inoculated with seed pieces in glass plates by micropipette and incubated for two weeks at room temperature $\left(28^{0}-30^{\circ} \mathrm{C}\right)$. Production level of aflatoxin on kernel pieces by each isolate of A. flavus was measured by observing illumination of seed pieces under UV light. Two virulent isolates of $A$. flavus (Is 1 and Is 2) were selected based on illumination under UV and stored in PDA slants for further studies.

\section{Screening of genotypes for resistance to aflatox- in production:}

Two experiments were conducted in maha 2006/07 in two locations at Maha Illuppallama to evaluate maize genotypes for resistance to Aspergillus infection and aflatoxin production under artificial inoculation of $A$. flavus and natural infection (without inoculation). In both Experiments, maize seeds were planted in beds of $3 \mathrm{~m} \times 1.5 \mathrm{~m}$ at a spacing of $60 \mathrm{~cm} \times 30 \mathrm{~cm}$ as recommended by Department of Agriculture (DOA), Sri Lanka (Technoguide, 1990). Cultural and agronomic practices were done according to the DOA recommendations. The treatments were laid out in a randomized complete block design (RCBD) as a two factor (maize accessions and natural infection or artificial inoculation of Aspergillus) factorial experiment with three replicates. A. flavus isolate Is 1 and Is 2 were selected on the basis of virulence and conidia suspension used for inoculation was prepared by mixing conidia suspensions of two isolates. Conidia for inoculation were obtained from cultures of two isolates of $\mathrm{A}$. fla$v u s$ on PDA, incubated for 14 days at room temperature $\left(28^{0}-30^{\circ} \mathrm{C}\right)$. Conidia were harvested by adding $10 \mathrm{ml}$ sterile distilled water (SDW) to the each culture dish of isolates Is 1 and Is 2 which were then gently shaken. The suspension of isolates Is 1 and Is2 was blended with SDW and filtered through double layered cheesecloth. Two drops of Tween 20 per $100 \mathrm{ml}$ were added. Concentration of conidia in the final suspension was measured using a hemacytometer and adjusted to the $1 \times 10^{6}$ conidia $/ \mathrm{ml}$ with SDW (Campbell and White 1995). Conidial suspension was prepared immediately prior to use. Primary ears of each plant were inoculated at the silk growth stage $(100 \%$ ears with emerged silks) using a hand operated sprayer. Ten $\mathrm{ml}$ of conidial suspension were sprayed onto silk and through the husk into kernels of each ear. Unsprayed plots were served as the control. After harvesting, six ears in center row were collected from each plot and sundried for 7 days to use for the analysis of aflatoxin production by Enzyme linked-immunosorbent assay (ELISA) (Campbell and White 1995). Percentage kernel infection of each treatment by Aspergillus were measured by plating of randomly collected 50 kernels of each plot on PDA and subsequent growing of Aspergillus on medium during 7 days incubation at room temperature. Data on aflatoxin production level and percentage kernel infection were statistically analyzed using the SAS software package.

\section{Experiment 1:}

An experiment was conducted in maha 2006/07 at Maha Illuppallama with different maize accessions (genotypes). Seven lines (CML numbers) which were resistant to Aspergillus infection received from International Maize and Wheat Improvement Center (CIMMIYT), seventeen locally collected germplasm and one commercial hybrid (Sampath) were used for evaluation of genotypes for resistance to Aspergillus infection and subsequent aflatoxins production under artificial inoculation with isolates of Aspergillus and under noninoculation. Mixture of conidia suspension of Is 1 and Is 2 were used for inoculation.

\section{Experiment 2:}

An experiment was conducted in maha 2006/07 at Maha Illuppallama with different maize accessions (genotypes). Twenty hybrids, developed by combining seven CIMMIYT Aspergillus resistant inbred lines with 3 promising local inbred lines (KI numbers) and 3 commercial hybrids (NK 40, sampath and pacific) were used for evaluation for resistance to Aspergillus infection and aflatoxins production under artificial inoculation with isolates of Aspergillus and under non-inoculation. Mixture of conidia suspension of Is 1 and Is 2 were used for inoculation.

\section{Quantification of aflatoxin on maize kernels:}

Aflatoxin was quantified at the Horticultural Crops Research and Development Institute, Peradeniya by ELISA. ELISA kits were purchased from International Diagnostic Systems Crop (IDS), 2620 S. Cleveland Ave., Suite 100; PO Box 799, St. Joseph, MI 49085, USA. The IDS ELISA is a solid phase immunoassay designed to detect aflatoxns in food or feedstuffs. The test is performed in micro-wells coated with a high affinity capture antibody to aflatoxins. Aflatoxin was extracted from $50 \mathrm{~g}$ of kernels of each treatment using the Holaday-Velasco methodology (International Diagnostic Systems Crop, USA). An extracted samples were added to the wells followed by an enzyme conjugate and 
incubated to enzyme conjugate competes with aflatoxin in the sample for binding sites on the antibody coated well. ELISA plates were washed to remove any unbound material and substrate was added for the color development process. The colour intensity is inversely proportional to the amount of aflatoxins present in the sample. Results were obtained by reading the absorbance of the wells with a microplate reader using $450 \mathrm{~nm}$ filter. Levels of aflatoxins were quantified by comparison of absorbance values and standard light absorbance curves of plates of IDS ELISA kits. Values of aflatoxin production $(\mathrm{ppb})$ on kernels of maize accessions were calculated and recorded as 0 (no aflatoxin), 10 $(20 \mathrm{ppb}>$ aflatoxin $>10 \mathrm{ppb})$ and $50(100 \mathrm{ppb}>$ aflatoxin $>50 \mathrm{ppb}$ ) (Table 2 and 3 ).

\section{RESULTS AND DISCUSSION}

Isolates of Aspergillus collected from infected kernels of maize were identified by comparison of their colony morphology on PDA with published data. $A$. flavus (green mould) were identified mainly by morphology and mycelia colour of the isolates on PDA (Kenneth, et al. 1973). Isolates produced a yellow green colour mycelium on PDA at early stages (at 5 days) which later became dark green after 14 days having reverse colony colour dark brown. Conidial heads radiate, splitting into several columns. Morphological characters of mycelia, conidia and conidial heads were similar to description of A. flavus published by International Mycological Institute, UK (Anon, 1966). Isolates were evaluated for their ability to produce aflatoxins on maize seeds by UV light test. All collected isolates of Aspergillus flavus had the ability to produce aflatoxin in association with maze kernels (Table 1) and this indicate that many virulent isolates of $A$. flavus may occur in maize growing areas in the dry zone.

Table 1: Aflatoxin production ability of isolates of Aspergillus flavus in association with maize kernels of hybrid variety sampath.

\begin{tabular}{llc}
\hline $\begin{array}{c}\text { Isolates of } \\
\text { Aspergillus } \\
\text { flavus }\end{array}$ & $\begin{array}{c}\text { Area of isolate } \\
\text { collection }\end{array}$ & $\begin{array}{c}\text { Aflatoxin production } \\
\text { based }^{\text {on illumination }} \\
\text { of seeds }^{\mathrm{a}}\end{array}$ \\
\hline Is 1 & Anuradhapura & +++ \\
Is 2 & Maha Illuppalla- & +++ \\
& ma & +++ \\
Is 3 & Dambulla & +++ \\
Is 4 & Laggala & ++ \\
Is 5 & Pallegema & ++ \\
Is 6 & Monaragala & ++ \\
\hline
\end{tabular}

a - Illumination of inoculated kernel pieces under UV +++ Kernel pieces brightly illuminated

++ Kernel pieces illuminated
Genetic resistance for $A$. flavus infection is the most economical and successful way to controlling infection and subsequent production of aflatoxin (Lillehoj 1987). Screening of available maize genotypes under field conditions is the appropriate technique for selecting resistant genotypes for Aspergillus infection. In experiment 1 , there was a significant interaction between Aspergillus inoculation and maize accessions indicating that different accessions responded differently to different inoculation methods. In general mean percentage kernel infection by Aspergillus was increased with artificial inoculation. Commercial hybrid "Sampath" showed significantly higher kernel infection under artificial inoculation compared to other tested genotypes but all inbread lines and germplasm tested

Table 2: Mean percentage of kernel infection and values of aflatoxin production (ppb) on kernels of maize accessions when artificially inoculated with Aspergillus flavus and non-inoculated condition in maha 2006/07.

\begin{tabular}{|c|c|c|c|c|}
\hline \multirow[t]{2}{*}{$\begin{array}{l}\text { Maize acces- } \\
\text { sion } \\
\end{array}$} & \multicolumn{2}{|c|}{$\begin{array}{l}\text { Inoculated with Aspergillus } \\
\text { flavus }\end{array}$} & \multicolumn{2}{|c|}{ Non-inoculated } \\
\hline & \multicolumn{2}{|c|}{ Infection $^{\mathrm{a}}(\%)$ levels $^{\mathrm{b}}(\mathrm{ppb})$} & $\begin{array}{l}\text { Kernal } \\
\text { Infection }^{\mathrm{a}} \\
\quad(\%)\end{array}$ & $\begin{array}{c}\text { Aflatox- } \\
\text { in Lev- } \\
\text { els }{ }^{b} \\
\text { (ppb) }\end{array}$ \\
\hline CML 338 & 22 & 50 & 14 & 0 \\
\hline No 29b & 28 & 50 & 08 & 10 \\
\hline No 27 & 34 & 50 & 08 & 10 \\
\hline No 47ra & 34 & 50 & 16 & 10 \\
\hline CML 326 & 36 & 50 & 12 & 0 \\
\hline No 20 & 36 & 50 & 16 & 10 \\
\hline No $29 a$ & 36 & 50 & 10 & 10 \\
\hline No 6 & 38 & 50 & 14 & 0 \\
\hline No. $45 \mathrm{mu}$ & 38 & 50 & 14 & 10 \\
\hline No 49da & 38 & 50 & 18 & 10 \\
\hline CML 269 & 40 & 50 & 20 & 50 \\
\hline No 7 & 40 & 50 & 18 & 50 \\
\hline No 44 & 42 & 50 & 12 & 10 \\
\hline No 12 & 44 & 50 & 14 & 10 \\
\hline CML 176 & 46 & 50 & 24 & 50 \\
\hline CML 343 & 46 & 50 & 26 & 50 \\
\hline CML 289 & 48 & 50 & 22 & 50 \\
\hline No11a & 48 & 50 & 14 & 10 \\
\hline No 46ra & 48 & 50 & 22 & 50 \\
\hline No 48ma & 52 & 50 & 12 & 10 \\
\hline CML 342 & 56 & 50 & 16 & 10 \\
\hline No $11 \mathrm{~b}$ & 56 & 50 & 12 & 10 \\
\hline No 21 & 56 & 50 & 16 & 10 \\
\hline No 13 & 58 & 50 & 16 & 50 \\
\hline Sampath & 62 & 50 & 16 & 10 \\
\hline \multicolumn{5}{|c|}{ LSD $(p=0.05)$ for Kernal infection $\%$} \\
\hline \multicolumn{5}{|c|}{ Factor 1 (Accession) $=12.8$} \\
\hline \multicolumn{5}{|c|}{ Factor 2 (Inoculation) $=16.3$} \\
\hline \multicolumn{5}{|c|}{$\begin{array}{l}\text { Interaction }(\mathrm{A} \times \mathrm{I}) \quad=5.8 \\
\mathrm{CV}(\%)-23.8\end{array}$} \\
\hline \multirow{3}{*}{\multicolumn{5}{|c|}{$\begin{array}{l}\mathrm{CV}(\%)-23.8 \\
\mathrm{a}-\text { Means of percentage kernel infection } \\
\mathrm{b}-\text { Means of aflatoxin levels }(\mathrm{ppb})\end{array}$}} \\
\hline & & & & \\
\hline & & & & \\
\hline \multicolumn{5}{|c|}{$\begin{array}{l}0=\text { No aflatoxin } 10=20 \mathrm{ppb}>\text { Aflatoxin }>10 \mathrm{ppb} \quad 50=100 \\
\text { ppb }>\text { Aflatoxin }>50 \mathrm{ppb}\end{array}$} \\
\hline $\begin{array}{l}\text { Data on aflatox } \\
\text { and therefore it }\end{array}$ & in levels has & $\begin{array}{l}y \text { three figure } \\
\text { ed to statistic }\end{array}$ & $n$ all & ieties \\
\hline
\end{tabular}


produced $50 \mathrm{ppb}$ aflatoxin level under artificial inoculation with $A$. flavus. There were no significant relationship between percentage kernels infection and aflatoxin production levels of different genotypes under non-inoculated condition $(\mathrm{r}=0.49)$. Inbred lines CML 326, 338 and germplasm No 6 were only accessions that showed resistance to aflatoxin production under non-inoculated condition. Others showed susceptibility because they produced aflatoxins over 10 or $50 \mathrm{ppb}$ even under noninoculated condition (Table 2).

Experiment 2 also showed a significant interaction between Aspergillus inoculation and maize accessions indicating that different accessions showed different responses to different inoculation methods. In general, mean percentage kernel infection by Aspergillus was increased by artificial inoculation compare to non-inoculation (Table 3). New hybrid combination KI42-6 x CML326 and commercial hybrid pacific showed significantly higher kernel infection compared to other tested hybrids under inoculation and produced over $50 \mathrm{ppb}$ aflatoxin levels. However, there were no significant relationship between percentage kernels infection and aflatoxin production levels of different hybrids under artificial inoculation or non-inoculation $(\mathrm{r}=$ 0.40 and 0.24 respectively). Out of 23 hybrids, 15 were produced comparatively higher aflatoxin levels over $10 \mathrm{ppb}$ under artificial inoculation. Although, there was Aspergillus infection on the kernels, new hybrids CML20 x CML 289, CML20 x CML 342, CML20 x CML 343, KI32-9 X CML 176, KI32-9 x CML322, KI32-9 x CML342 and KI42-6 x CML269 did not show aflatoxin production under artificial inoculation. Commercial hybrids Pacific and Sampath showed aflatoxin production levels over 10 or $50 \mathrm{ppb}$ under inoculated and non-inoculated conditions indicating that commercial hybrids were susceptible to aflatoxin production. There were kernel infections by Aspergillus of all the tested hybrids including Pacific, Sampath and KI42-6 x CML269. However, except Pacific, Sampath and K142-6xCML269, all the other hybrids showed resistance to aflatoxin production under non-inoculated condition.

Results in both experiments indicated that $A$. flavus is pathogenic and environment at Maha Illuppallama often is more than optimal for disease development of most of the genotypes. Wound inoculation techniques for germplasm screening for aflatoxin production have also been suggested (Campbell and White, 1995, King and Scott 1982). However, wounding circumvents the silk channel, destroy the kernel aleurone and pericarp and disturb the proteaceous activity which is important for resistance of kernels (Zhengyu et al. 1997). Wounding of ears may break down resistant mechanisms and as a results some genotypes may be incorrectly rated as susceptible when the resistant mechanisms is expressed through characteristics of silks, pericarp or aleurone layer (Darrah et al. 1987)

Results also indicated that genetic resistance for aflatoxin production could not be found in commercial hybrids grown in Sri Lanka. Identification of new genotypes that can consistently show high level of resistance to aflatoxin production is necessary for future maize improvement programs. Some inbred lines and hybrids used in the present study showed resistance to aflatoxin production. Level of kernel infection and aflatoxin production of different genotypes were frequently changed with environments, inoculation methods and their interactions (Campbell and White 1995, Zuber et al. 1983) and therefore, genotype should be evaluated in different environments over years to generate sufficient data to accurately identify resistant genotypes.

Table 3: Mean percentage kernel infection and values of aflatoxin production (ppb) on kernels of maize genotypes when artificially inoculated with Aspergillus flavus and non-inoculated condition in maha 2006/07.

\begin{tabular}{lcccc}
\hline \multicolumn{1}{c}{ Maize accession } & \multicolumn{2}{c}{$\begin{array}{c}\text { Inoculated with } \\
\text { Aspergillus flavus }\end{array}$} & \multicolumn{2}{c}{ Non-inoculated } \\
\cline { 2 - 5 } & $\begin{array}{c}\text { Kernel } \\
\text { Infection } \\
(\%)\end{array}$ & $\begin{array}{c}\text { Aflatoxin } \\
\text { Levels }\end{array}$ & $\begin{array}{c}\text { Kernal } \\
\text { (ppb) }\end{array}$ & $\begin{array}{c}\text { Aflatoxin } \\
\text { I\%) }\end{array}$ \\
\hline CML 20 x CML 326 & 16 & 10 & 12 & 0 \\
CML 20 x CML 289 & 18 & 0 & 12 & 0 \\
KI32-9 x CML 342 & 18 & 0 & 14 & 0 \\
KI32-9 x CML 176 & 20 & 0 & 08 & 0 \\
CML 20 x CML 338 & 22 & 10 & 08 & 0 \\
KI32-9 x CML 289 & 22 & 50 & 20 & 0 \\
CML 20 x CML 342 & 24 & 0 & 10 & 0 \\
CML 20 x CML 269 & 26 & 10 & 06 & 0 \\
CML 20 x CML 343 & 26 & 0 & 14 & 0 \\
KI32-9 x CML 326 & 26 & 0 & 18 & 0 \\
KI32-9 x CML 343 & 26 & 0 & 12 & 0 \\
KI42-6 x CML 342 & 28 & 10 & 18 & 0 \\
NK 40 & 28 & 10 & 18 & 0 \\
KI32-9 x CML 269 & 30 & 10 & 08 & 0 \\
KI32-9 x CML 338 & 30 & 50 & 22 & 0 \\
CML 20 x CML 176 & 32 & 10 & 18 & 0 \\
KI42-6 x CML 338 & 32 & 50 & 16 & 0 \\
KI42-6 x CML 269 & 34 & 0 & 20 & 10 \\
Sampath & 34 & 50 & 20 & 50 \\
KI42-6 x CML 176 & 36 & 10 & 08 & 0 \\
KI42-6 x CML 289 & 36 & 10 & 14 & 0 \\
Pacific & 42 & 50 & 18 & 50 \\
KI42-6 x CML 326 & 44 & 50 & 10 & 0 \\
Mean & 28.26 & & 14.09 & \\
\hline
\end{tabular}

$\operatorname{LSD}(\mathrm{p}=0.05)$ for Kernal infection $\%$

Factor 1 (Accession) $=24.8$

Factor 2 (Inoculation $)=17.5$

Interaction $(\mathrm{I} \times \mathrm{A}) \quad=4.3$

CV (\%) $-12.3 \%$

a - Means of percentage kernel infection

$\mathrm{b}$ - Means of aflatoxin levels (ppb)

$0=$ No aflatoxin $10=20 \mathrm{ppb}>$ Aflatoxin $>10 \mathrm{ppb} 50=100$ $\mathrm{ppb}>$ Aflatoxin $>50 \mathrm{ppb}$

Data on aflatoxin levels has only three figures in all varieties and therefore it was not subjected to statistical analysis. 


\section{CONCLUSIONS}

Many virulent isolates of Aspergillus flavus may occur in maize growing areas in the dry zone. Artificial inoculation assured the kernel infection and aflatoxin production in maize. No relationship between kernel infection and aflatoxin production was found in maize so that screening of accessions for resistance to aflatoxin production has to be done under inoculated condition measuring aflatoxin level in the kernel. Hybrids CML20 x CML 289, CML20 x CML 342, CML20 x CML 343, KI32-9 x CML 176, KI32-9 x CML322, KI32-9 x CML342 and KI42-6 x CML269 were found to be resistant to aflatoxin production.

\section{ACKNOWLEDGEMENT}

Grateful acknowledgements are made to Sri Lanka Council for Agriculture Research Policy for the financial assistance provided for this study.

\section{REFERENCES}

AgStat 2006 Socio Economic and Planning Center. Department of Agriculture, Peradeniya, Sri Lanka.

Anon. 1966 Descriptions of Pathogenic fungi and bacteria, No. 91, CMI Publications, UK.

Campbell KW and White DG 1995 Evaluation of corn genotype for resistance to Aspergillus ear rot, kernel infection, and aflatoxin production. Plant Disease, 79(10): 1039-1045.

Darrah LL, Lillehoj EB, Zuber MS, Scott GE, G Thompson, West GR, Widstrom NW and Fortnum BA 1987 Inheritance of aflatoxin B1 levels in maize kernel under modified natural inculation with Aspergillus flavus. Crop Science, 27:869-872.
Davis ND, Currier CG and Diener UL 1986 Aflatoxin contamination of corn hybrids in Alabama. Cereal Chemistry, 63:467-470.

Diener UL, Cole RG, Sanders TH, Payne GA, Lee LS and Clich MA 1987 Epidemiology of aflatoxin formation by Aspergillus flavus. Annu. Rev. Phytopathol. 25:249-270.

Hoejskov CS and Joergensen K 1996 Aflatoxin B1, B2, G1 and G2 in maize, peanut butter, and cocoa. Soeborg (Denmark). LST. 1996, 15p.

Kenneth B, Raper, Dorothy I Fennel and Peter K. C Austwick 1973 The genes Aspergillus,

Robert E. Krieger publishing company, Huntington, New York, 13-55.

King SB and Scott GE 1982 Field inoculation techniques to evaluate maize for reaction to kernel infection by Aspergillus flavus. Phytopathology 72:782-785.

Lillehoj EB 1987 The aflatoxin in maize problem: The historical perspective. in: $\quad$ M. $\quad$ S. Zuber, E. B. Lillehoj and B. L. Renfro, (eds). Aflatoxin in maize: Proc. Workshop. 13-32 International maize and wheat improvement center, Mexico, DF.

Technoguide 1990 Crop Recommendations Technoguide, Department of Agriculture, Sri Lanka, $1-3 p$.

Zhengyu Huang, Donald G, White and Gary N. Payne 1997 Corn seed proteins inhibitory toAspergillus flavus and aflatoxin biosynthesis. Phytopathology, 87 (6): 622-627.

Zuber MS, Darrah LL, Lillehoj EB, Josephson ML, Manwiller A, Scott GE, Gudauskas RG, Homer ES, Widstrom NW, Thompson DL, Bockholt AL and Brewbaker JL 1983 Comparison of open -pollinated maize varieties and hybrids for preharvest aflatoxin contamination in the southern United States, Plant Disease, 67:185-187. 